\title{
bm0611174
}

\section{Single crystals of V-amylose complexed with $\alpha$-naphthol}

Mateus B. Cardoso, Jean-Luc Putaux*, Yoshiharu Nishiyama, William Helbert, Martin Hÿtch, Nádya P. Silveira and Henri Chanzy

\section{SUPPORTING INFORMATION}

Table 1. List of reflections observed in electron diffraction patterns recorded at room temperature on untilted and tilted single crystals. The corresponding $d$-spacings $\left(d_{o b s}\right)$ are compared with the values $\left(d_{c a l}\right)$ calculated from the parameters of the refined unit cell.

\begin{tabular}{|c|c|c|c|}
\hline$h k l$ & $d_{\mathrm{obs}}(\mathrm{nm})$ & $d_{\text {cal }}(n m)$ & $\left|d_{\text {obs }}-d_{\text {cal }}\right|(\mathrm{nm})$ \\
\hline 200 & 1.157 & 1.161 & 0.004 \\
\hline 210 & 1.042 & 1.039 & 0.003 \\
\hline 220 & 0.824 & 0.822 & 0.002 \\
\hline 310 & 0.736 & 0.735 & 0.001 \\
\hline 320 & 0.646 & 0.645 & 0.001 \\
\hline 400 & 0.582 & 0.581 & 0.001 \\
\hline 221 & 0.570 & 0.569 & 0.001 \\
\hline 410 & 0.565 & 0.563 & 0.002 \\
\hline 330 & 0.546 & 0.548 & 0.002 \\
\hline 311 & 0.538 & 0.538 & 0.000 \\
\hline 420 & 0.520 & 0.520 & 0.000 \\
\hline 321 & 0.500 & 0.499 & 0.001 \\
\hline 430 & 0.466 & 0.465 & 0.001 \\
\hline 411 & 0.459 & 0.458 & 0.001 \\
\hline 510 & 0.456 & 0.455 & 0.001 \\
\hline 421 & 0.436 & 0.434 & 0.002 \\
\hline 520 & 0.432 & 0.431 & 0.001 \\
\hline 440 & 0.409 & 0.411 & 0.002 \\
\hline 530 & 0.396 & 0.399 & 0.003 \\
\hline 511 & 0.395 & 0.395 & 0.000 \\
\hline 600 & 0.390 & 0.391 & 0.001 \\
\hline 610 & 0.383 & 0.382 & 0.001 \\
\hline 620 & 0.369 & 0.368 & 0.001 \\
\hline
\end{tabular}




\begin{tabular}{|c|c|c|c|}
\hline 540 & 0.362 & 0.362 & 0.000 \\
\hline 601 & 0.349 & 0.348 & 0.001 \\
\hline 630 & 0.348 & 0.347 & 0.001 \\
\hline 611 & 0.337 & 0.344 & 0.007 \\
\hline 621 & 0.333 & 0.333 & 0.000 \\
\hline 550 & 0.329 & 0.329 & 0.000 \\
\hline 710 & 0.328 & 0.329 & 0.001 \\
\hline 640 & 0.323 & 0.322 & 0.001 \\
\hline 720 & 0.320 & 0.319 & 0.001 \\
\hline 730 & 0.306 & 0.305 & 0.001 \\
\hline 641 & 0.299 & 0.298 & 0.001 \\
\hline 650 & 0.298 & 0.298 & 0.000 \\
\hline 721 & 0.296 & 0.296 & 0.000 \\
\hline 800 & 0.292 & 0.291 & 0.001 \\
\hline 740 & 0.289 & 0.288 & 0.001 \\
\hline 810 & 0.289 & 0.288 & 0.001 \\
\hline 442 & 0.287 & 0.284 & 0.003 \\
\hline 731 & 0.285 & 0.285 & 0.000 \\
\hline 532 & 0.280 & 0.280 & 0.000 \\
\hline 820 & 0.278 & 0.282 & 0.004 \\
\hline 651 & 0.278 & 0.278 & 0.000 \\
\hline 660 & 0.273 & 0.274 & 0.001 \\
\hline 830 & 0.272 & 0.272 & 0.000 \\
\hline 750 & 0.271 & 0.270 & 0.001 \\
\hline 622 & 0.269 & 0.269 & 0.000 \\
\hline 840 & 0.260 & 0.260 & 0.000 \\
\hline 661 & 0.260 & 0.259 & 0.001 \\
\hline 831 & 0.257 & 0.257 & 0.000 \\
\hline 910 & 0.257 & 0.256 & 0.001 \\
\hline 552 & 0.253 & 0.253 & 0.000 \\
\hline 712 & 0.253 & 0.256 & 0.003 \\
\hline 760 & 0.252 & 0.252 & 0.000 \\
\hline 920 & 0.250 & 0.252 & 0.002 \\
\hline 642 & 0.250 & 0.249 & 0.001 \\
\hline 850 & 0.246 & 0.246 & 0.000 \\
\hline 930 & 0.245 & 0.245 & 0.000 \\
\hline 770 & 0.235 & 0.235 & 0.000 \\
\hline 860 & 0.233 & 0.232 & 0.001 \\
\hline 1000 & 0.232 & 0.232 & 0.000 \\
\hline 822 & 0.229 & 0.229 & 0.000 \\
\hline 1020 & 0.225 & 0.228 & 0.003 \\
\hline 1050 & 0.208 & 0.208 & 0.000 \\
\hline
\end{tabular}




\begin{tabular}{llll}
1022 & 0.197 & 0.197 & 0.000 \\
1200 & 0.192 & 0.193 & 0.001 \\
1400 & 0.168 & 0.166 & 0.002 \\
1460 & 0.153 & 0.153 & 0.000 \\
\hline
\end{tabular}


Table 2. List of a selection of non-overlapping $d$-spacings observed in synchrotron X-ray diffraction diagrams recorded on dry mats of $V_{\alpha}$-naphthol crystals. The corresponding $d$-spacings $\left(d_{\text {obs }}\right)$ are compared with the values $\left(d_{c a l}\right)$ calculated from the parameters of the refined unit cell.

\begin{tabular}{cccc}
\hline$h k l$ & $d_{\mathrm{obs}}(\mathrm{nm})$ & $d_{\mathrm{cal}}(\mathrm{nm})$ & $\left|d_{\mathrm{obs}}-d_{\mathrm{cal}}\right|(\mathrm{nm})$ \\
\hline 200 & 1.1359 & 1.1359 & 0.0000 \\
320 & 0.6301 & 0.6339 & 0.0038 \\
101 & 0.7382 & 0.7360 & 0.0022 \\
111 & 0.7021 & 0.7019 & 0.0002 \\
201 & 0.6433 & 0.6446 & 0.0013 \\
211 & 0.6190 & 0.6193 & 0.0003 \\
\hline
\end{tabular}

